\title{
Repair of Common Carotid Artery Injury with an External Carotid Artery Flap
}

\author{
Sami Asfar ${ }^{a, b}$ Jasem Al-Alia Moneera Ben-Nakhi ${ }^{a}$ \\ a Vascular Surgery Unit, Department of Surgery, Mubarak AI-Kabeer Teaching Hospital and \\ ${ }^{b}$ Department of Surgery, Faculty of Medicine, Kuwait University, Kuwait
}

\section{Key Words}

Carotid artery injury - Vascular injury of the neck .

Patch angioplasty $\cdot$ latrogenic vascular injury

\begin{abstract}
Objectives: To describe a new technique to repair injuries of the common carotid artery. Clinical Presentation and Intervention: A 30-year-old man sustained an iatrogenic injury to the left common carotid artery during surgical dissection of a left branchial cyst. The artery was repaired as follows: the left external carotid artery was ligated distally, its stump was longitudinally opened to create an arterial flap, which was then used to repair the defect in the common carotid artery. The patient remained free of any symptoms throughout 1 year of follow-up. Conclusion: Use of an external carotid flap provides an alternative method of repairing an injured carotid artery.
\end{abstract}

Copyright (C) 2004 S. Karger AG, Basel

\section{Introduction}

The incidence of blunt carotid artery injuries is about 1 per 1,000 cases of blunt trauma to the neck [1], whereas penetrating carotid artery injuries due to knives and bullets account for $4-17 \%[2,3]$. An increased number of iatrogenic vascular injuries have been reported following the introduction of angiography, interventional radiology and invasive monitoring $[4,5]$. In a review of 71 iatrogenic arterial injuries, carotid artery injuries accounted for $5.6 \%$ of the cases [6], all of which were due to the inadvertent introduction of catheters into the carotid artery during placement of lines in the internal jugular vein. Iatrogenic carotid injuries due to surgery, however, are rarely reported, and no mention of them was found in three major reviews of carotid artery injuries [7-9]. Here we report an injury to the common carotid artery during the dissection of a neck mass in a young man and describe a new technique for the repair of the artery.

\section{Case Report}

A 30-year-old male presented to the General Surgery Out-Patient Department with a left-sided neck swelling, which was gradually increasing in size over the previous 2 months. Clinical examination revealed a $5 \times 6 \mathrm{~cm}$ mass in the left anterior cervical triangle partly beneath the sternocleidomastoid muscle. It was mobile, firm, smooth and not tender, and there was no thrill. A bruit was heard over the mass. There was no cervical lymphadenopathy. Ultrasound examination of the neck revealed a large solid mass with a cystic space. Routine blood work was normal. Carotid duplex scan and thyroid ultrasound were normal. Fine-needle aspiration cytology revealed scanty mesenchymal tissue.

Under general anaesthesia the mass was explored through an incision along the anterior border of the left sternocleidomastoid muscle. The mass was cystic in nature and adherent to the sheath of the left

\begin{tabular}{ll}
\hline KARGER & ( 2004 S. Karger AG, Basel \\
Fax +4161306 1234 & 1011-7571/04/0135-0292\$21.00/0 \\
$\begin{array}{l}\text { E-Mail karger@karger.ch } \\
\text { www.karger.com }\end{array}$ & $\begin{array}{l}\text { Accessible online at: } \\
\text { www.karger.com/mpp }\end{array}$
\end{tabular}

Prof. Sami Asfar, MB,CHB, MD (UK), FRCSEd, FACS

Department of Surgery, Faculty of Medicine

Kuwait University, PO Box 24923

13110 Safat (Kuwait)

Tel. +965 531 9475, Fax +965 531 9597, E-Mail sami@hsc.kuniv.edu.kw 
common carotid artery. During dissection sudden arterial bleeding occurred from the common carotid artery. Heparin 3,000 units was given intravenously and vascular clamps applied to the common carotid artery. It was found that the common carotid artery was denuded of all its layers except the intima from the bifurcation to about $2 \mathrm{~cm}$ proximally. In the upper half of this denuded area and just below the bifurcation, the intima was torn (fig. 1a).

The denuded intima was excised and the injury site was freshened to result in a defect in the anterior wall of the common carotid artery $2 \mathrm{~cm}$ long and involving about $25 \%$ of its circumference (fig. 1b). The external carotid artery was mobilised and its first branch, the superior thyroid artery, was ligated. The external carotid artery was ligated distally and transected. The stump of the external carotid artery was then longitudinally incised to create an arterial flap. The flap was reflected down over the common carotid artery and fashioned to cover the defect. The repair was made with continuous 6/0 Prolene suture (fig. 1c, d). Postoperative anticoagulant therapy was continued for 7 days along with aspirin $320 \mathrm{mg} /$ day. The patient had an uneventful recovery, with no neurologic defect. Postoperative carotid duplex scanning and CT brain scans were normal. The patient has been followed up in the vascular surgery clinic regularly for 1 year and remains free of any symptoms, and repeat duplex scan of the carotids was normal. Histopathology of the removed mass was consistent with the diagnosis of a branchial cyst.

\section{Discussion}

In a recent report on the management of major vascular injuries to the neck, carotid artery injuries accounted for about $17 \%$ of all patients presenting with penetrating neck injuries [3]. Injuries to the external carotid artery are usually managed by ligation. Internal and common carotid artery injuries are managed by primary repair or interposition graft (saphenous vein or synthetic graft).

Surgical iatrogenic carotid injuries are rarely reported, as no mention of such injuries was found in three major reviews of carotid artery injuries [7-9]. In this report involving an injury to the common carotid artery during the dissection of a neck mass in a young man, primary suturing of the injury would have caused stenosis of the artery. Instead, we used the transected ipsilateral external carotid artery as a flap to cover the defect in the common carotid artery. The other option was to use saphenous vein or a synthetic (PTFE, Dacron) patch. We opted not to use such patches because long-term follow-up of patients after carotid endarterectomy and patching has been associated with a few complications [10-12]: patch dilatation to twice the original diameter was seen in 17 and 9\% of vein and PTFE patches, respectively [10]. Vein patch rupture was reported in $0.5 \%$ in a series of 1,691 patients [11]. Pseudoaneurysm, secondary infections and spontaneous rupture are other, albeit uncommon, reported complications [12]. We felt that the use of this arterial flap
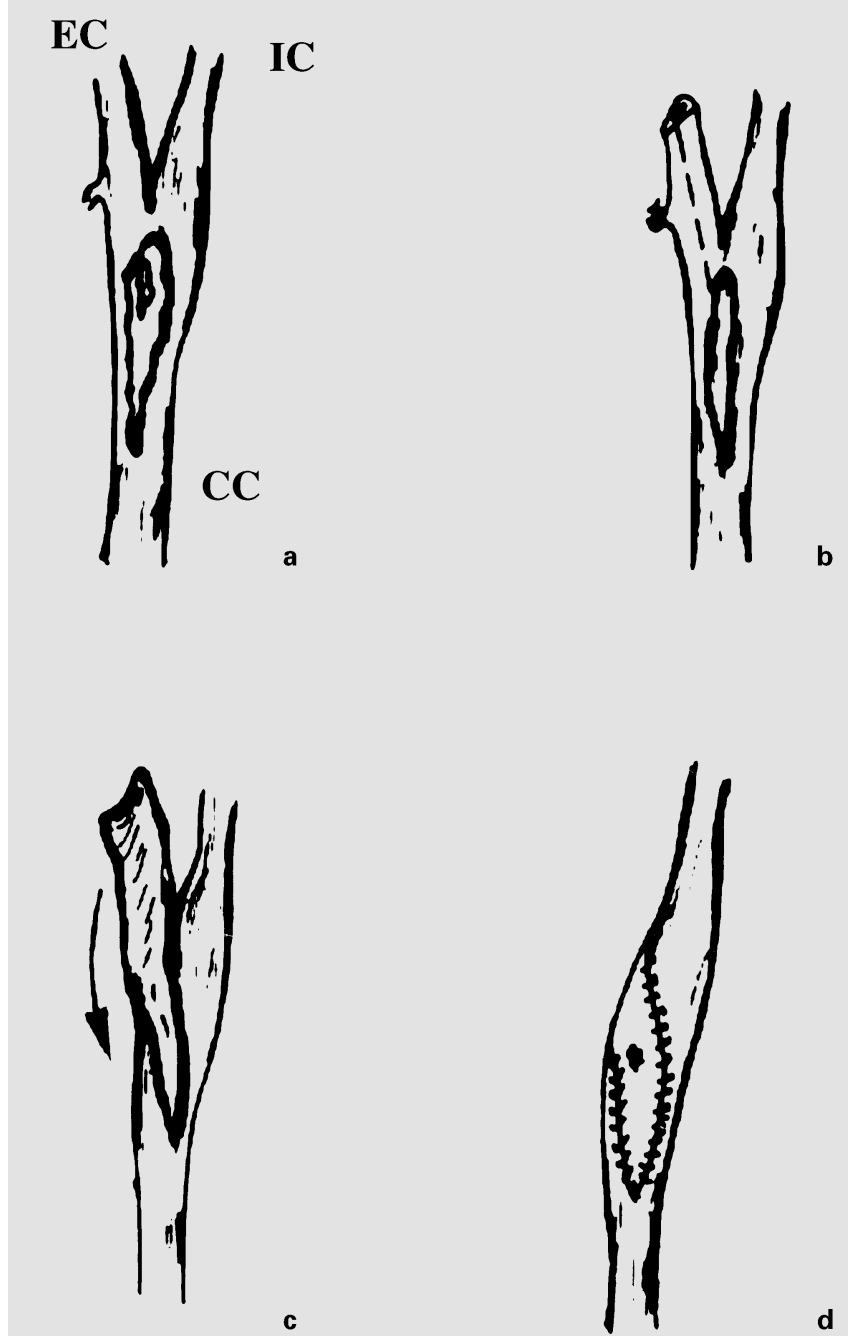

d

Fig. 1. a Damage to the common carotid (CC) artery. The intima is exposed due to removal of the adventitia and medial layers of the artery. At the top end of the damaged vessel wall there was an irregular tear in the intima. b The exposed intima of the CC artery was excised and the wound edges freshened. The superior thyroid artery was ligated at its origin. The distal end of the external carotid (EC) artery was ligated and the artery was transected. The stump of the EC artery was longitudinally opened (along the dotted line). c The EC artery stump splayed open to form a flap. d The EC artery flap rotated down over the defect in the CC artery, fashioned and sutured with continuous 6/0 Prolene.

would avoid any possible long-term complication associated with vein or synthetic patch. Moreover, since the patient is young and has healthy vessels, sacrifice of the ipsilateral external carotid artery probably would not have any aftereffects. 


\section{Conclusion}

An external carotid artery flap provides an alternative method to repair common carotid artery injuries in young patients, when primary repair is unattainable.

\section{Acknowledgement}

The authors thank Prof. Abdulla Behbehani for giving permission to publish this case.

\section{References}

1 Davis JW, Holbrook TL, Hoyt DB, Mackersie RC, Field TO, Shackford SR: Blunt carotid artery dissection: Incidence, associated injuries, screening, and treatment. J Trauma 1990; 30:1514-1517.

2 Reynolds RR, McDowell HA, Diethelm AG: The surgical treatment of arterial injuries in the civilian population. Ann Surg 1979;189:700708.

3 Mittal VK, Paulson TJ, Colaiuta E, Habib FA, Penney DG, Daly B, Young SC: Carotid artery injuries and their management. J Cardovasc Surg 2000;41:423-431.

4 Adar R, Bass A, Walden R: Iatrogenic complications in surgery: Five years experience in general and vascular surgery in a university hospital. Ann Surg 1982;196:725-729.
5 Gollub MJ, Friedwald JP, Hartigan M: Iatrogenic dissection of the common carotid artery: Diagnosis by dynamic image and color flow Doppler ultrasonography. J Clin Ultrasound 1991;19:250-253.

6 Mills JL, Wiedeman JE, Robison JG, Hallett JW: Minimizing mortality and morbidity from iatrogenic arterial injuries: The need for early recognition and prompt repair. J Vasc Surg 1986;4:22-27.

7 Fry RE, Fry WJ: Extracranial carotid artery injuries. Surgery 1980;88:581-587.

8 Fabian TC, George SM, Croce MA, Mangiante EC, Voeller GR, Kudsk KA: Carotid artery trauma: Management based on mechanism of injury. J Trauma 1990;30:953-963.
9 Li MS, Smith BM, Espinosa J, Brown RA, Richardson $\mathrm{P}$, Ford R: Nonpenetrating trauma to the carotid artery: Seven cases and a literature review. J Trauma 1994;36:265-272.

10 Lord RS, Raj TB, Stary DL, Nash PA, Graham $\mathrm{AR}$, Goh KH: Comparison of saphenous vein patch, polytetrafluoroethylene patch and direct closure after carotid endarterectomy. Part I. Perioperative results. J Vasc Surg 1989;9:521529.

11 O'Hara PJ, Hertzer NR, Krajewski LP, Beven EG: Saphenous vein patch rupture after carotid endarterectomy. J Vasc Surg 1992;15:504509.

12 Hertzer NR: Non-stroke complications of carotid endarterectomy; in Bernhard VM, Towne J (eds): Complications in Vascular Surgery, ed 2. Orlando, Grune \& Stratton, 1985. 